\title{
Endoscopic ultrasound-guided tissue sampling of small subepithelial tumors of the upper gastrointestinal tract with a 22-gauge core biopsy needle
}

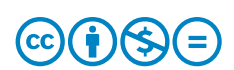

\author{
Authors \\ Christoph Schlag ${ }^{1}$, Christoph Menzel ${ }^{1}$, Manuela Götzberger ${ }^{2}$, Simon \\ Nennstiel ${ }^{1}$, Peter Klare ${ }^{1}$, Stefan Wagenpfeil ${ }^{3}$, Roland M. Schmid ${ }^{1}$, \\ Gregor Weirich ${ }^{4,}$, , Stefan von Delius ${ }^{1, *}$ \\ Institutions \\ 1 II. Medizinische Klinik, Klinikum rechts der Isar, Technische \\ Universität München, Munich, Germany \\ 2 Gastroenterologie, Klinikum Freising, Akademisches \\ Lehrkrankenhaus der Technischen Universität München, \\ Freising, Germany \\ 3 Institut für Medizinische Biometrie, Epidemiologie und \\ Medizinische Informatik, Universität des Saarlandes, Campus \\ Homburg, Homburg, Germany \\ 4 Institut für Allgemeine Pathologie und Pathologische Anatomie, \\ Technische Universität München, Munich, Germany
}

submitted 18.5.2016

accepted after revision 13.9.2016

\author{
Bibliography \\ DOI http://dx.doi.org/10.1055/s-0042-119948 | \\ Endoscopy International Open 2017; 05: E165-E171 \\ (c) Georg Thieme Verlag KG Stuttgart · New York \\ ISSN 2364-3722
}

Corresponding author

PD Dr. med. Christoph Schlag, II. Medizinische Klinik und Poliklinik, Klinikum rechts der Isar der Technischen Universität München, Ismaninger Straße 22, 81675 München, Germany Fax: 089-4140-4871

Christoph.Schlag@mri.tum.de

\section{ABSTRACT}

Background and study aims The optimal approach to small subepithelial tumors (SETs) of the upper gastrointestinal tract remains inconclusive. The aim of this study was to evaluate endoscopic ultrasound-guided fine needle biopsy (EUS-FNB) for less invasive tissue sampling of small SETs of the upper gastrointestinal tract.

Patients and methods In this prospective observational study patients with small $(\leq 3 \mathrm{~cm})$ SETs of the upper gastrointestinal tract were eligible and underwent EUS-FNB with a 22-gauge core biopsy needle. The main outcome measure was the diagnostic yield. The number of obtained core biopsies was also assessed.

Results Twenty patients were included. The mean SET size was $16 \mathrm{~mm}$ (range 10-27 mm). EUS-FNB was technically feasible in all cases and no complications were observed. The diagnostic yield was $75 \%$. Core biopsy specimens were obtained in only $25 \%$ of cases.

Conclusion EUS-FNB with a 22-gauge core biopsy needle of small SETs can achieve a definite diagnosis in the majority of cases. However, because core samples cannot regularly be obtained, EUS-FNB seems not to be convincingly superior to standard EUS-FNA in this setting

\section{Introduction}

Subepithelial tumors (SETs) of the upper gastrointestinal tract are mostly detected incidentally during upper gastrointestinal endoscopy with an estimated prevalence of $0.4 \%$ [1]. They include broad differential diagnoses of benign as well as potentially and overtly malignant lesions. Endoscopic ultrasound (EUS) is the best imaging modality for further evaluation of SETs. However, it does not allow definite discrimination of benign from malignant lesions [2,3]. As larger SETs $(>3 \mathrm{~cm})$ should rather primarily be resected due to their higher malignant potential, the optimal approach to smaller lesions $(\leq 3 \mathrm{~cm})$ remains inconclusive [4]. On one hand, due to their lower malignant potential, surveillance of small SETs by periodic EUS examinations seems reasonable but might be a strain for many patients and still carries the risk of delayed diagnosis of poten- tial malignancy. On the other hand, endoscopic or surgical resection of small lesions might be an overtreatment in case of truly benign findings. Thus, obtaining histopathologic diagnosis of small lesions by less invasive tissue sampling such as EUS-guided fine-needle aspiration (EUS-FNA) seems a reasonable approach. However, EUS-FNA of SETs might often be limited by insufficient amount and quality of specimen obtained [5]. Recently, a core biopsy needle with a reverse bevel has been developed to overcome such limitations [6], but so far this needle has been rarely assessed for tissue sampling of SETs. Moreover, only limited data are available, which focused on EUS-guided tissue sampling on particular small SETs. Thus, we evaluated EUS-guided fine-needle biopsy (EUS-FNB) with a 22-gauge core biopsy needle of small SETs of the upper gastrointestinal tract.

* equally contributed 


\section{Patients and methods}

\section{Study population}

In this prospective study consecutive patients who presented with suspected small SETs of the upper gastrointestinal tract were enrolled. To be included in the study patients had to be age $\geq 18$ years and had to give written informed consent. SETs, which were defined as a circumscribed mass in continuity with the gastrointestinal wall located under the epithelial layer, were supposed to have maximum size of $3 \mathrm{~cm}$ and not to be classified truly benign (such as homogenous hyperechoic lipoma or homogenous anechoic cyst) as determined by EUS. Exclusion criteria were refusal to provide informed consent, pregnancy, and general contraindications for EUS-FNB such as platelet count under 50000 , prothrombin time under $50 \%$ or double anti-platelet medication. The study protocol was approved by the local ethics committee and registered at ClinicalTrials.gov (Identifier: NCT01726010).

\section{Study procedure}

All procedures were performed with the patients under procedural sedation placed in the left lateral decubitus position. EUS were performed by one highly experienced endosonographer (S.D.) using a radial scanning echoendoscope (Pentax EG3670URK, Hamburg, Germany). All lesions were characterized by size, suspected origin layer, and echotexture. Based on these findings a suspected prior EUS-FNB diagnosis was made. An additional linear array echoendoscope (Pentax EG-3870UTK, Hamburg, Germany) was used in case of EUS-FNB. EUS-FNB was carried out with a disposable 22-gauge core biopsy needle (EchoTip ProCore, Wilson-CookMedical, Winston-Salen, NA, USA): After endosonographically visualisation of the targeted lesion the needle was inserted into the tumor under endosonograhic guidance. Once the needle was within the lesion the stylet was removed and suction was applied using a $10-\mathrm{mL}$ syringe while moving the needle back and forth within the lesion for at least 5 times. Finally suction was released and the needle was withdrawn from the lesion. After the procedure the patients were hospitalized for 1 night and monitored for possible postprocedural complications such as abdominal pain, infection, bleeding or other symptoms.

\section{Cytohistological assessment}

To produce a smear for cytologic evaluation a single drop of the aspirated material was transferred to glass slides by using the stylet and the rest of the material was placed in $50 \%$ ethanol for further cell block processing by flushing the needle with Ringer's solution. For most of the procedures rapid on-site cytologic examination (ROSE) was carried out. In these cases the slides were stained with a quick panoptic stain (Hemacolor, Merck Millipore, Darmstadt, Germany) and assessed immediately under the microscope (Olympus CX31, Hamburg, Germany) by one experienced cytopathologist (G.W.) The procedure was terminated when the cytopathologist verified that an adequate sample could have been obtained. Otherwise the procedure was repeated with a maximum number of five needle passes.
If the cytopathologist was not present on site, 3 passes were routinely performed and the air-dried slides and cell block material were sent to the cytopathology department for further analyses. The obtained material was assessed for further morphologic (HE stained) and if feasible and indicated for immunhistochemical analysis. Primary antibodies used were CD117, CD-34, DOC-1, Desmin and S-100, Synaptophysin, Pancytokeratin and MIB-1. A peroxidase conjugate secondary antibody visualized primary antibody reactions.

\section{Outcome measures}

The primary outcome measure was the diagnostic yield of EUSFNB defined as the proportion of patients in whom a definite tissue diagnosis could be obtained. In addition, technical feasibility and possible complications of the procedure, examiner's satisfaction with handling, and visualization of the needle (rated on a numeric rating scale from 1-10) and number of core biopsies were assessed.

\section{Statistical analysis}

For quantitative data mean, standard deviation and ranges are presented. Qualitative data are expressed in absolute and relative frequencies. Microsoft Excel (Microsoft Cooperation, Redmond, WA, USA) was used for data handling.

\section{Sample size estimation}

In our study we estimated that EUS-FNB of small SETs would reach a diagnostic yield of $80 \%$. Thus we ended up with a sample size of $n=20$ considering the following calculation: When the sample size is 20 , a 2 -sided $95 \%$ confidence interval for a single proportion will extend $17.5 \%$ from the observed proportion for an expected proportion of $80 \%$. In addition, a 1-group $x^{2}$ test with a 0.052 -sided significance level will have $80 \%$ power to detect the difference between the Null hypothesis proportion of $50 \%$ and the alternative proportion of $80 \%$ when the sample size is 20 . Sample size calculation was done by nQuery, version 7.0 (Statistical Solutions, Cork, Ireland).

\section{Follow up}

Follow up after EUS-FNB was carried out as follows: In case of suspected or potential malignancy (except metastasis), in case of non-diagnostic material and in case of symptoms endoscopic or surgical resection of the SET was recommended. In case of a benign tissue diagnosis or in case of metastasis no resection was recommended and EUS follow up after 6 months was carried out.

\section{Results}

During the study period between September 2012 and December 201450 patients with suspected SET $\leq 3 \mathrm{~cm}$ were screened for study eligibility. Twelve of these patients were excluded because EUS revealed impression on the outer gastric wall instead of a truly SET. Of the remaining 38 patients with EUS-proven SETs, 8 patients were excluded because EUS detected truly benign lesions (lipoma, $n=7$; cyst, $n=1$ ) and in 2 patients SETs were measured $>3 \mathrm{~cm}$. Eight patients refused to participate in 
the study. Finally, 20 patients fulfilled all of the inclusion and none of the exclusion criteria ( $\triangleright$ Fig. 1 ).

The mean age of the 20 participants (female, $n=11$; male, $\mathrm{n}=9$ ) was $58.4 \pm 15.0$ years (range $29-78$ years). The mean tumor size was $16.0 \pm 5.0 \mathrm{~mm}$ (range: $10-27 \mathrm{~mm}$ ). SETs were located in the esophagus $(n=3)$, stomach $(n=14)$ and duodenum $(n=3)$, respectively. Nine tumors were supposed to have originated in the submucosa (third layer) and 11 in the muscularis propria (fourth layer). The characteristics of the 20 SETs are summarized in $>$ Table $\mathbf{1}$.

The mean number of EUS-FNB passes were $2.6 \pm 1.2$ (range $1-5)$. Neither technical failure nor complications were observed in any case. Examiner's satisfaction with handling and visualization of the needle was $6.5 \pm 3.3$ points (range $1-10$ points) and $6.5 \pm 3.7$ points (range $1-10$ points), respectively.

EUS-FNB provided a definite diagnosis in $15 / 20$ cases $(n=4$ : leiomyoma; $n=3$ : lipoma; $n=2$ : cyst; $n=2$ : metastasis of squamous cell carcinoma [SCC]; $n=1$ : gastrointestinal stromal tumor [GIST]; $n=1$ : neuroendocrine tumor [NET]; $n=1$ : ectopic pancreas; $n=1$ : inflammatory fibroid polyp [IFP]), resulting in a diagnostic yield of $75 \%$. Core biopsies were obtained in only 5/20

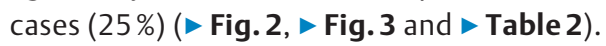

Immunhistochemical staining was needed for a definite diagnosis in $7 / 15$ (47\%) cases whereas in 8/15 (53\%) cases a definite diagnose could be made without immunhistochemistry.

There was no difference in diagnostic yield whether ROSE was available or not. However, a lower number of needle passages were needed with ROSE $(2.3 \pm 1.4)$ versus without ROSE $(3,0 \pm 0)$.

\section{Follow up}

Of the 15 patients with a definite tissue diagnosis 3 were followed up by resection due to suspected malignancy in 2 patients (GIST, $n=1 ;$ NET, $n=1$ ) and due to symptoms in 1 patient with an esophageal leiomyoma. Ten patients with benign tissue diagnoses were followed up by EUS after 6 months, which showed constant size of the SETs in all 10 patients $(n=3$ : leiomyoma; $n=3$ : lipoma; $n=2$ : cyst; $n=1$ : ectopic pancreas; $n=1$ : IFP). Two patients with metastasis of squamous cell carcinoma were also followed up by EUS, which showed decreased size after radiotherapy in both cases.

Of the 5 non-diagnostic cases 2 patients underwent surgical resection, which showed a final diagnosis of GIST in both patients. The remaining 3 patients refused the recommended resection and EUS follow up after 6 months was performed instead, which showed constant size of the SETs in all cases ( $\triangleright$ Table 2).

\section{Discussion}

We conducted a prospective study, which evaluated EUS-guided tissue sampling of small SETs $(<3 \mathrm{~cm})$ of the upper gastrointestinal tract using a 22-gauge core biopsy needle. A definite diagnosis could be performed in $75 \%$ of patients.

Previous EUS-FNA-studies on SETs of the upper gastrointestinal tract of all sizes have found various diagnostic yields ranging from $38 \%$ to $89 \%[5,7-11]$. It has been assumed that EUS-

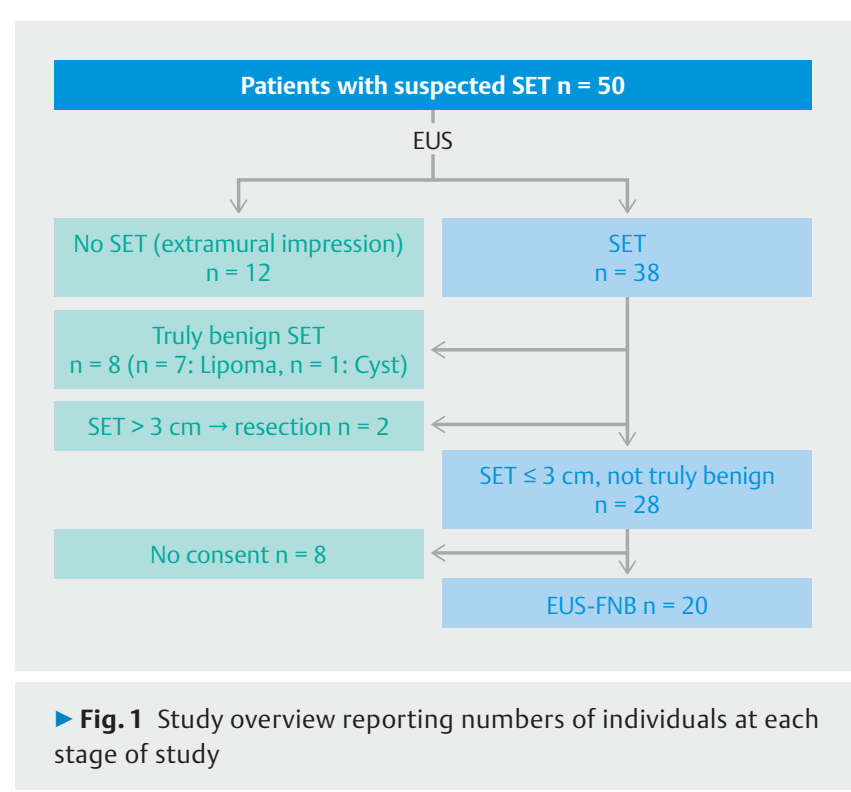

FNA with standard needles might often be limited by insufficient amount and quality of specimens obtained [5]. Thus, EUS-guided Trucut biopsy (EUS-TCB) has been developed to obtain better tissue specimens, but again, various diagnostic yields ranging from $55 \%$ to $78 \%$ have been reported [12-15]. In 1 randomized crossover study EUS-TCB was not superior to EUS-FNA due to its high rate of technical failure in this setting [13], whereas another study reported a superior diagnostic yield of a 19-gauge Trucut needle compared to a 22-gauge standard needle in gastric SETs $>2 \mathrm{~cm}$ [14]. However, particularly in small SETs EUS-TCB does not seem a good option due to the limitation of the rigidity of its 19-gauge caliber and difficult maneuverability. In our study a 22-gauge core biopsy needle was used, which might overcome limitations of EUS-FNA regarding tissue acquisition and of EUS-TCB regarding maneuverability [6]. In a recent comparative study Kim et al. found a significantly higher yield rate of obtained core biopsies of $75 \%$ for the 22 -gauge core biopsy needle compared to only $20 \%$ for the standard 22-gauge FNA needle in 22 patients with gastric SETs $\geq 2 \mathrm{~cm}$ [16]. These findings were confirmed by Lee et al. who reported in a retrospective study on 77 patients with SETs $>2 \mathrm{~cm}$ a diagnostic yield of $82 \%$ and core biopsy tissue in $97 \%$ of these patients [17]. In our study evaluating small SETs we observed a comparable diagnostic yield of $75 \%$, but core biopsies could be obtained in substantially fewer patients (33\%). Most likely this can be explained by the average tumor size of only $16 \mathrm{~mm}$ in our study (compared to $32 \mathrm{~mm}$ and $28 \mathrm{~mm}$ in the former studies) as obtaining core biopsies is expected to be more difficult in smaller lesions. In addition, our study cohort comprised many patients with lesions other than mesenchymal GISTs or leiomyoma such as lipoma, ectopic pancreas or IFP, from which obtaining a core biopsy might be more difficult and 2 patients with cysts, in which core biopsies per se were not possible.

In our study only patients with small SETs $(\leq 3 \mathrm{~cm})$ were included. In our opinion EUS-guided tissue sampling seems not to be beneficial in most lesions $>3 \mathrm{~cm}$ due to their high potential for malignancy and the consequent need to recommend 
- Table 1 Characteristics of 20 SETs

\begin{tabular}{|c|c|c|c|c|c|c|}
\hline$\#$ & Location & Size $(\mathrm{mm})$ & Layer & Appearance & Suspected diagnosis prior EUS-FNB & Diagnosis after EUS-FNB \\
\hline 1 & Esophagus & 24 & 4th & $\begin{array}{l}\text { hypoechoic } \\
\text { homogenous }\end{array}$ & Leiomyoma & Leiomyoma \\
\hline 2 & Corpus & 27 & 4th & $\begin{array}{l}\text { hypoechoic } \\
\text { heterogenous }\end{array}$ & GIST & Cyst \\
\hline 3 & Cardia & 19 & 4th & $\begin{array}{l}\text { hypoechoic } \\
\text { homogenous }\end{array}$ & Leiomyoma & Leiomyoma \\
\hline 4 & Esophagus & 17 & 4th & $\begin{array}{l}\text { hypoechoic } \\
\text { homogenous }\end{array}$ & Leiomyoma & Metastasis (SCC) \\
\hline 5 & Cardia & 20 & $3 r d$ & $\begin{array}{l}\text { hyperechoic } \\
\text { hetrogenous }\end{array}$ & Lipoma & Lipoma \\
\hline 6 & Corpus & 12 & 4th & $\begin{array}{l}\text { hypoechoic } \\
\text { heterogenous }\end{array}$ & GIST & GIST \\
\hline 7 & Bulbus duodeni & 10 & $3 r d$ & $\begin{array}{l}\text { hyperechoic } \\
\text { heterogenous }\end{array}$ & Lipoma & Not known \\
\hline 8 & Antrum & 18 & 4th & $\begin{array}{l}\text { hypoechoic } \\
\text { heterogenous }\end{array}$ & GIST & Not known \\
\hline 9 & Bulbus duodeni & 15 & $3 r d$ & $\begin{array}{l}\text { hypoechoic } \\
\text { homogenous }\end{array}$ & NET & NET \\
\hline 10 & Antrum & 12 & $3 r d$ & $\begin{array}{l}\text { hypoechoic } \\
\text { homogenous }\end{array}$ & Ectopic pancreas & Cyst \\
\hline 11 & Corpus & 11 & 4th & $\begin{array}{l}\text { hyperechoic } \\
\text { heterogenous }\end{array}$ & GIST & Lipoma \\
\hline 12 & Antrum & 12 & $3 r d$ & $\begin{array}{l}\text { hypoechoic } \\
\text { homogenous }\end{array}$ & Ectopic pancreas & Ectopic pancreas \\
\hline 13 & Bulbus duodeni & 10 & $3 r d$ & $\begin{array}{l}\text { hyperechoic } \\
\text { heterogenous }\end{array}$ & Lipoma & IFP \\
\hline 14 & Corpus & 12 & 4 th & $\begin{array}{l}\text { hypoechoic } \\
\text { homogenous }\end{array}$ & Leiomyoma & Not known \\
\hline 15 & Antrum & 18 & 4th & $\begin{array}{l}\text { hyperechoic } \\
\text { heterogenous }\end{array}$ & GIST & Lipoma \\
\hline 16 & Antrum & 25 & $3 r d$ & $\begin{array}{l}\text { hyperechoic } \\
\text { heterogenous }\end{array}$ & Ectopic pancreas & Not known \\
\hline 17 & Antrum & 11 & $3 r d$ & $\begin{array}{l}\text { hypoechoic } \\
\text { heterogenous }\end{array}$ & Ectopic pancreas & Not known \\
\hline 18 & Esophagus & 14 & $3 r d$ & $\begin{array}{l}\text { hyperechoic } \\
\text { hetrogenous }\end{array}$ & Metastasis & Metastasis (SCC) \\
\hline 19 & Cardia & 16 & 4th & $\begin{array}{l}\text { hypoechoic } \\
\text { homogenous }\end{array}$ & Leiomyoma & Leiomyoma \\
\hline 20 & Cardia & 16 & 4th & $\begin{array}{l}\text { hypoechoic } \\
\text { homogenous }\end{array}$ & Leiomyoma & Leiomyoma \\
\hline
\end{tabular}

SET, subepithelial tumor; GIST, gastrointestinal stromal tumor; EUS-FNB, endoscopic ultrasound-guided fine-needle biopsy; SCC, squamous cell carcinoma; IFP, inflammatory fibroid polyp

surgery. Otherwise, the optimal approach to $\mathrm{SETs} \leq 3 \mathrm{~cm}$ still remains inconclusive [4]. On the one hand their malignant potential is considered to be low, so that regularly performed endosonographic surveillance might be an option, particularly when $<2 \mathrm{~cm}$ in size [18]. Supporting this recommendation, Song et al. recently found no risk of progression for most incidental small
SETs in the upper gastrointestinal tract in a large retrospective study [19]. On the other hand, surveillance strategies often require life-long follow-up adherence by patients, which has been reported to be very poor [20] and always carries the risk of delayed diagnosis of malignancy. Notably, even for small SETs, rapid growth and early metastasis to the liver have been de- 

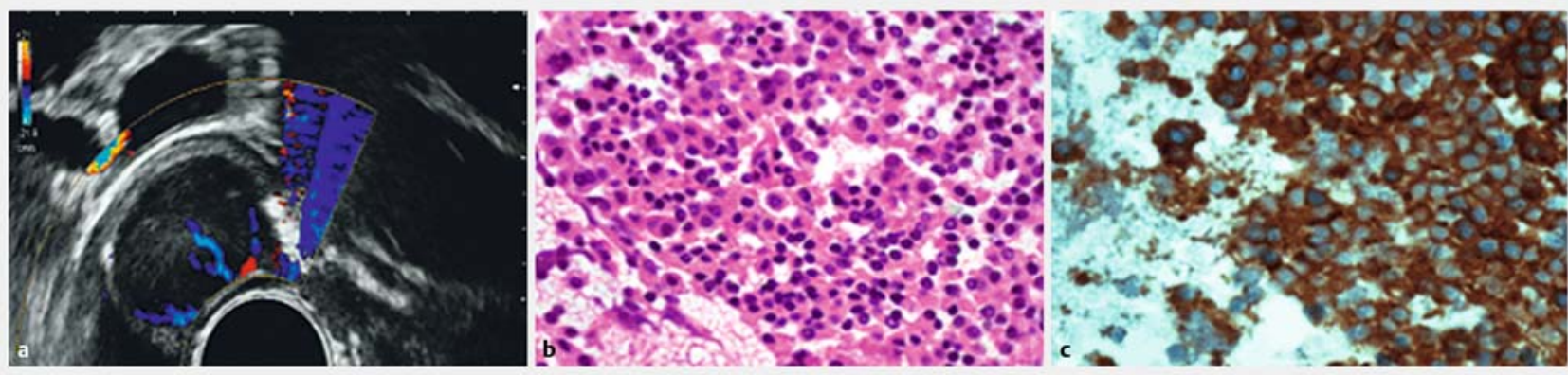

- Fig. 2 Patient with neuroendocrine tumor. a EUS showing homogenous hypoechoic SET in the duodenal bulb with clear perfusion in the color Doppler mode. b EUS-FNB-acquired tissue showing cell clusters with eosinophilic cytoplasm and round nuclei with salt \& pepper chromatin (HE stained, $\times 200)$. c Imunohistochemical positivity for synaptophysin (x200)
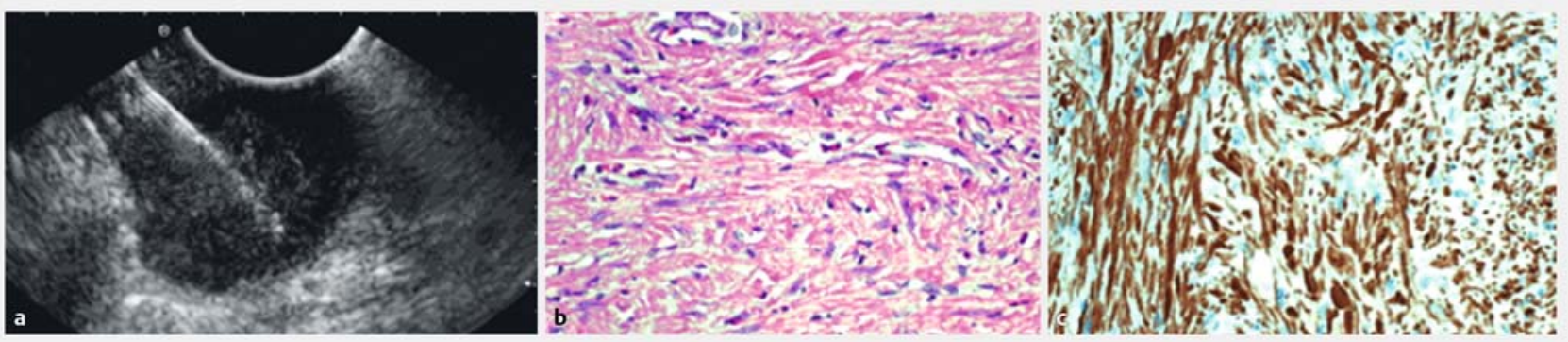

- Fig. 3 Patient with leiomyoma. a EUS-FNB of a homogenous hypoechoic SET of the stomach. $\mathbf{b}$ EUS-FNB-aquired tissue showing a spindle cell population (HE stained, $\times 200$ ). c Imunohistochemical positivity for desmin $(\times 200)$. Negativity for DOG1, CD117 and CD34 (not shown).

scribed [21]. Moreover, EUS alone is mostly not able to reliably discriminate benign from malignant lesions regardless if they are located in the third or fourth layer, perhaps except from homogenous hyperechoic lipomas and homogenous anechoic cysts $[2,3,22]$. This was confirmed by the findings of our current study, in which the overall agreement of EUS-suspected and final tissue diagnosis (by FNB or resection) was only $53 \%$ (in 9/17 cases) even including 2 cysts (which had been diagnosed by EUS as GIST and ectopic pancreas, respectively) and 2 lipomas (which had been diagnosed by EUS as GISTs). It is possible that advanced EUS imaging techniques such as contrastenhanced EUS or real-time elastography may be helpful for more accurate prediction in the future, but there has been not enough evidence yet to on which to definitely rely [23,24].

As shown in the current study, EUS-guided tissue sampling seems to be a good less-invasive option to obtain a definite diagnosis of small SETs, which was possible in the majority (75\%) of patients with a mean SET-diameter of $16 \mathrm{~mm}$. Akahoshi et al., who also focused on small SETs (mean diameter $15 \mathrm{~mm}$ ), found a comparable diagnostic rate of $73 \%$. But in contrast to our study, a 22-gauge standard FNA needle was used [25]. Larghi et al. also reported a sufficient diagnostic yield of $82 \%$ in a subgroup of patients with small subepithelial lesions (mean diameter $14 \mathrm{~mm}$ ) using a 19-gauge standard FNA needle and a special forward-viewing linear echoendoscope [26]. These findings and the low number of core biopsies obtained in our study raise the question of whether the core needle as used in our study is substantially superior to standard FNA needles in small SETs. In particular, the distance between the tip of the core needle and the end of the side port, which measures $6 \mathrm{~mm}$ in the 22-gauge version, might be a limitation for tissue sampling of very small lesions. Irrespective of the needle type small SETs are generally difficult to puncture due to bending of the wall and drifting of the SET during the puncture. To overcome such limitations a new technique of EUS-FNA using a forward-viewing echoendoscope with an attached cap device has been described recently, which may be even more successful in lesions $<10 \mathrm{~mm}$ [27].

Alternatively, various minimal invasive surgical as well as endoscopic resection techniques have been described for obtaining a definitive tissue diagnosis of small SETs [28-33]. These techniques may be particularly good options for malignant or potentially malignant lesions such as NETs or GISTs but are rather an overtreatment for truly benign lesions such as lipoma, ectopic pancreas, IFP or leiomyoma. Thus, prior less-invasive EUS-guided tissue sampling could help to better differentiate patients with suspected malignancy, who should then rather undertake complete resection of the tumor, from patients with truly benign lesions, who do not require further follow-up examinations. For example, in our study $11 / 20$ patients (55\%) with truly benign lesions would not have needed further surveillance.

Our study was subject to some limitations. First, we used an observational study design without a control group. Thus, it 
- Table 2 Diagnostic procedures and outcomes in SETs

\begin{tabular}{|c|c|c|c|c|c|c|c|}
\hline \# & ROSE & $\begin{array}{l}\text { Smear } \\
\text { Cytology }\end{array}$ & Cell block & $\begin{array}{l}\text { Core } \\
\text { available }\end{array}$ & IHC & Tissue diagnosis & Follow-Up \\
\hline 1 & yes & yes & yes & no & yes & Leiomyoma & resection: Leiomyoma \\
\hline 2 & yes & yes & not performed & no & not performed & Cyst & EUS: constant size \\
\hline 3 & yes & yes & yes & yes & yes & Leiomyoma & EUS: constant size \\
\hline 4 & yes & yes & yes & yes & yes & Metastasis (SCC) & EUS: decreasing size (after RTx) \\
\hline 5 & yes & yes & yes & no & not performed & Lipoma & EUS: constant size \\
\hline 6 & no & yes & yes & yes & yes & GIST & resection: GIST \\
\hline 7 & yes & NSM & NSM & no & NSM & not possible & EUS: constant size \\
\hline 8 & yes & NSM & NSM & no & NSM & not possible & EUS: constant size \\
\hline 9 & yes & yes & yes & yes & yes & NET & resection: NET \\
\hline 10 & yes & yes & not performed & no & not performed & Cyst & EUS: constant size \\
\hline 11 & yes & yes & yes & no & not performed & Lipoma & EUS: constant size \\
\hline 12 & yes & yes & yes & no & not performed & Ectopic pancreas & EUS: constant size \\
\hline 13 & no & yes & yes & no & not performed & IFP & EUS: constant size \\
\hline 14 & yes & NSM & NSM & no & NSM & not possible & EUS: constant size \\
\hline 15 & no & yes & NSM & no & not performed & Lipoma & EUS: constant size \\
\hline 16 & no & NSM & NSM & no & NSM & not possible & resection: GIST \\
\hline 17 & no & yes & NSM & no & NSM & not possible & resection: GIST \\
\hline 18 & no & yes & yes & no & yes & Metastasis (SCC) & EUS: decreasing size (after RTx) \\
\hline 19 & no & yes & yes & yes & yes & Leiomyoma & EUS: constant size \\
\hline 20 & no & yes & yes & no & yes & Leiomyoma & EUS: constant size \\
\hline
\end{tabular}

cannot be concluded that the core needle as used in our study provides better results than a standard needle for obtaining a tissue diagnosis of small SETs. Second, although we used a needle that had been developed for a primary histologic work up [6] we relied on a combination of smear cytology and cell block analysis. Similar approaches have already been successfully used in previous studies [34,35]. However, such an approach always requires a very experienced cytologist which has a significant impact on diagnostic accuracy. Thus, it has to be mentioned that in our study, the majority of tissue diagnoses were based on cytopathology and adequate histologic material (core biopsy specimens) was obtained in substantially fewer patients. Moreover, ROSE was used in the majority of cases, which also has been shown to have a positive impact on diagnostic yields [36], but might not be generally available. Third, tissue diagnoses were confirmed by resection (which can be regarded as the gold standard) in the minority of cases, whereas the majority of patients only received EUS follow up after 6 months. Because we regarded resection as an overtreatment for truly benign lesions we did not encourage patients to undergo lesion removal in cases that were suspected to be benign after EUS-guided tissue sampling. Moreover, in 3 cases in which no adequate mate- rial by EUS-FNB was obtained, the final diagnosis remained obscure, because these patients refused resection and EUS follow up was carried out instead. Because of these limitations only diagnostic yields can be reported in our study and no exact information about accuracy, sensitivity or specificity can be given.

\section{Conclusion}

In conclusion, EUS-FNB of small SETs of the upper gastrointestinal tract using a 22-gauge core biopsy needle provides a definite tissue diagnosis in the majority of cases. However, EUSFNB seems not to be substantially superior to standard EUSFNA in this setting as most diagnoses are based on cytopathology whereas core biopsies cannot regularly be obtained.

\section{Competing interests}

None 
[1] Hedenbro JL, Ekelund M, Wetterberg P. Endoscopic diagnosis of submucosal gastric lesions. The results after routine endoscopy. Surg Endosc 1991; 5: 20 - 23

[2] Hwang JH, Saunders MD, Rulyak S] et al. A prospective study comparing endoscopy and EUS in the evaluation of GI subepithelial masses. Gastrointest Endosc 2005; 62: 202 - 208

[3] Karaca C, Turner BG, Cizginer S et al. Accuracy of EUS in the evaluation of small gastric subepithelial lesions. Gastrointest Endosc 2010; 71: $722-727$

[4] Hwang JH, Rulyak SD, Kimmey MB et al. American Gastroenterological Association Institute technical review on the management of gastric subepithelial masses. Gastroenterology 2006; 130: 2217-2228

[5] Philipper M, Hollerbach S, Gabbert HE et al. Prospective comparison of endoscopic ultrasound-guided fine-needle aspiration and surgical histology in upper gastrointestinal submucosal tumors. Endoscopy 2010; 42: $300-305$

[6] Iglesias-Garcia J, Poley JW, Larghi A et al. Feasibility and yield of a new EUS histology needle: results from a multicenter, pooled, cohort study. Gastrointest Endosc 2011; 73: 1189-1196

[7] Vander Noot MR 3rd, Eloubeidi MA, Chen VK et al. Diagnosis of gastrointestinal tract lesions by endoscopic ultrasound-guided fine-needle aspiration biopsy. Cancer 2004; 102: 157- 163

[8] Hoda KM, Rodriguez SA, Faigel DO. EUS-guided sampling of suspected GI stromal tumors. Gastrointest Endosc 2009; 69: 1218 - 1223

[9] Mekky MA, Yamao K, Sawaki A et al. Diagnostic utility of EUS-guided FNA in patients with gastric submucosal tumors. Gastrointest Endosc 2010; 71: 913-919

[10] Williams DB, Sahai AV, Aabakken L et al. Endoscopic ultrasound guided fine needle aspiration biopsy: a large single centre experience. Gut 1999; 44: $720-726$

[11] Akahoshi K, Sumida Y, Matsui N et al. Preoperative diagnosis of gastrointestinal stromal tumor by endoscopic ultrasound-guided fine needle aspiration. World J Gastroenterol : WJG 2007; 13: 2077-2082

[12] Polkowski M, Gerke W, Jarosz D et al. Diagnostic yield and safety of endoscopic ultrasound-guided trucut [corrected] biopsy in patients with gastric submucosal tumors: a prospective study. Endoscopy 2009; 41: 329-334

[13] Fernandez-Esparrach G, Sendino O, Sole M et al. Endoscopic ultrasound-guided fine-needle aspiration and trucut biopsy in the diagnosis of gastric stromal tumors: a randomized crossover study. Endoscopy 2010; 42: $292-299$

[14] Na HK, Lee JH, Park YS et al. Yields and Utility of Endoscopic Ultrasonography-Guided 19-Gauge Trucut Biopsy versus 22-Gauge Fine Needle Aspiration for Diagnosing Gastric Subepithelial Tumors. Clin Endosc 2015; 48: $152-157$

[15] Lee JH, Choi KD, Kim MY et al. Clinical impact of EUS-guided Trucut biopsy results on decision making for patients with gastric subepithelial tumors $\geq 2 \mathrm{~cm}$ in diameter. Gastrointest Endosc 2011; 74: $1010-1018$

[16] Kim GH, Cho YK, Kim EY et al. Comparison of 22-gauge aspiration needle with 22-gauge biopsy needle in endoscopic ultrasonographyguided subepithelial tumor sampling. Scand J Gastroenterol 2014; 49: $347-354$

[17] Lee JH, Cho CJ, Park YS et al. EUS-guided 22-gauge fine needle biopsy for the diagnosis of gastric subepithelial tumors larger than $2 \mathrm{~cm}$. Scand J Gastroenterol 2015: DOI: 10.3109/00365521.2015.1052095

[18] Dumonceau JM, Polkowski M, Larghi A et al. Indications, results, and clinical impact of endoscopic ultrasound (EUS)-guided sampling in gastroenterology: European Society of Gastrointestinal Endoscopy (ESGE) Clinical Guideline. Endoscopy 2011; 43: 897-912

[19] Song JH, Kim SG, Chung S] et al. Risk of progression for incidental small subepithelial tumors in the upper gastrointestinal tract. Endoscopy 2015; 47: $675-679$

[20] Kushnir VM, Keswani RN, Hollander TG et al. Compliance with surveillance recommendations for foregut subepithelial tumors is poor: results of a prospective multicenter study. Gastrointest Endosc 2015; 81: $1378-1384$

[21] Tanaka J, Oshima T, Hori K et al. Small gastrointestinal stromal tumor of the stomach showing rapid growth and early metastasis to the liver. Dig Endosc: official journal of the Japan Gastroenterological Endoscopy Society 2010; 22: 354-356

[22] Rosch T, Kapfer B, Will U et al. Accuracy of endoscopic ultrasonography in upper gastrointestinal submucosal lesions: a prospective multicenter study. Scand J Gastroenterol 2002; 37: 856 - 862

[23] Dietrich CF, Jenssen C, Hocke M et al. Imaging of gastrointestinal stromal tumours with modern ultrasound techniques - a pictorial essay. Z Gastroenterol 2012; 50: 457-467

[24] Kannengiesser K, Mahlke R, Petersen F et al. Contrast-enhanced harmonic endoscopic ultrasound is able to discriminate benign submucosal lesions from gastrointestinal stromal tumors. Scand J Gastroenterol 2012; 47: $1515-1520$

[25] Akahoshi K, Oya M, Koga T et al. Clinical usefulness of endoscopic ultrasound-guided fine needle aspiration for gastric subepithelial lesions smaller than $2 \mathrm{~cm}$. JJ Gastrointestin Liver Dis: JGLD 2014; 23 : 405-412

[26] Larghi A, Fuccio L, Chiarello G et al. Fine-needle tissue acquisition from subepithelial lesions using a forward-viewing linear echoendoscope. Endoscopy 2014; 46: 39-45

[27] Yamabe A, Irisawa A, Bhutani MS et al. Usefulness of endoscopic ultrasound-guided fine-needle aspiration with a forward-viewing and curved linear-array echoendoscope for small gastrointestinal subepithelial lesions. Endosc Int Open 2015; 3: E161-164

[28] Hiki N, Yamamoto Y, Fukunaga T et al. Laparoscopic and endoscopic cooperative surgery for gastrointestinal stromal tumor dissection. Surg Endosc 2008; 22: 1729-1735

[29] Lee IL, Lin PY, Tung SY et al. Endoscopic submucosal dissection for the treatment of intraluminal gastric subepithelial tumors originating from the muscularis propria layer. Endoscopy 2006; 38: 1024- 1028

[30] Hwang JC, Kim JH, Kim JH et al. Endoscopic resection for the treatment of gastric subepithelial tumors originated from the muscularis propria layer. Hepatogastroenterology 2009; 56: 1281 - 1286

[31] Inoue H, Ikeda H, Hosoya T et al. Submucosal endoscopic tumor resection for subepithelial tumors in the esophagus and cardia. Endoscopy 2012; 44: $225-230$

[32] Xu MD, Cai MY, Zhou PH et al. Submucosal tunneling endoscopic resection: a new technique for treating upper Gl submucosal tumors originating from the muscularis propria layer (with videos). Gastrointest Endosc 2012; 75: 195 - 199

[33] Schlag C, Wilhelm D, von Delius S et al. EndoResect study: endoscopic full-thickness resection of gastric subepithelial tumors. Endoscopy 2013; 45: 4-11

[34] Bang JY, Hebert-Magee S, Trevino J et al. Randomized trial comparing the 22-gauge aspiration and 22-gauge biopsy needles for EUS-guided sampling of solid pancreatic mass lesions. Gastrointest Endosc 2012; 76: $321-327$

[35] Krishnan K, Dalal S, Nayar R et al. Rapid on-site evaluation of endoscopic ultrasound core biopsy specimens has excellent specificity and positive predictive value for gastrointestinal lesions. Dig Dis Sci 2013; 58: 2007-2012

[36] Polkowski M, Larghi A, Weynand B et al. Learning, techniques, and complications of endoscopic ultrasound (EUS)-guided sampling in gastroenterology: European Society of Gastrointestinal Endoscopy (ESGE) Technical Guideline. Endoscopy 2012; 44: 190-206 